\title{
Conhecimento e práticas em saúde bucal por cuidadores de idosos
}

\author{
Knowledge and practices in oral health by caregivers of elderly \\ Conocimiento y prácticas en salud bucal por cuidadores de idosos
}

\begin{abstract}
Luiza da Cunha Gomes ${ }^{1}$, Yêda Maria Parro ${ }^{1}$, Adriana Silva da Costa Cruz ${ }^{1}$ Érica Negrini Lia ${ }^{1}$, Andréa Mathes Faustino ${ }^{2 *}$.
\end{abstract}

\begin{abstract}
RESUMO
Objetivo: Identificar o conhecimento e práticas em saúde bucal realizada por cuidadores familiares de idosos. Método: Estudo transversal com 44 cuidadores de idosos que se encontravam em um hospital universitário do Distrito Federal. A coleta de dados foi entrevista individual com os cuidadores para identificar perfil sociodemográfico, informações sobre conhecimento acerca da higiene bucal e da percepção da saúde bucal do idoso cuidado. Resultados: A maioria dos cuidadores eram filhas dos idosos, sem formação específica para o cuidado. Cerca de $88 \%$ dos idosos utilizavam prótese dentária e $15 \%$ necessitavam de auxílio integral para a higiene bucal. Em $52 \%$ dos casos, as próteses dentárias eram higienizadas uma vez ao dia. Conclusão: A maioria dos idosos apresentou necessidade de auxílio para a higiene bucal, porém nem todos os cuidadores familiares o ofertavam de forma adequada. Cuidadores informais prevaleceram sem preparo ou orientação qualificada para prestar cuidados básicos de higiene bucal ao idoso.
\end{abstract}

Palavras Chaves: Cuidadores, Idoso fragilizado, Saúde bucal, Higiene bucal, Educação em saúde.

\begin{abstract}
Objective: to identify knowledge and practices in oral health carried out by family caregivers of the elderly. Method: a cross-sectional study with 44 elderly caregivers who were in a university hospital in the Federal District. The data collection was an individual interview with the caregivers to identify sociodemographic profile, information about knowledge about oral hygiene and the perception of oral health of the elderly care. Results: Most caregivers were daughters of the elderly, with no specific training for care. About $88 \%$ of the elderly used dental prostheses and $15 \%$ needed full oral hygiene assistance. In $52 \%$ of cases, dental prostheses were sanitized once a day. Conclusions: the majority of the elderly presented a need for help for oral hygiene; but not all family caregivers provided it adequately. Informal caregivers prevailed without preparation or qualified guidance to provide basic care of oral hygiene to the elderly.
\end{abstract}

Key words: Caregivers, Frail elderly, Oral health, Oral hygiene, Health education.

\section{RESUMEN}

Objetivo: identificar el conocimiento y prácticas en salud bucal realizada por cuidadores familiares de ancianos. Método: estudio transversal con 44 cuidadores de ancianos que se encontraban en un hospital universitario del Distrito Federal. La recolección de datos fue entrevista individual con los cuidadores para identificar perfil sociodemográfico, informaciones sobre conocimiento acerca de la higiene bucal y de la percepción de la salud bucal del anciano cuidado. Resultados: la mayoría de los cuidadores eran hijas de

\footnotetext{
${ }^{1}$ Departamento de Odontologia, Faculdade de Ciências da Saúde, Universidade de Brasília, Brasília-DF.

2 Departamento de Enfermagem, Faculdade de Ciências da Saúde, Universidade de Brasília, Brasília-DF.

*E-mail: andremathes@unb.br
} 
los ancianos, sin formación específica para el cuidado. Cerca del $88 \%$ de los ancianos utilizaban prótesis dentales y el $15 \%$ necesitaban ayuda integral para la higiene bucal. En el $52 \%$ de los casos, las prótesis dentales eran higienizadas una vez al día. Conclusión: la mayoría de los ancianos presentó necesidad de auxilio para la higiene bucal; pero no todos los cuidadores familiares lo ofrecían de forma adecuada. Los cuidadores informales prevalecieron sin preparación o orientación cualificada para prestar cuidados básicos de higiene bucal al anciano.

Palabras Claves: Cuidadores, Anciano frágil, Salud bucal, Higiene bucal, Educación en salud.

\section{INTRODUÇÃO}

O envelhecimento populacional é um fenômeno mundial decorrente do aumento da expectativa de vida e atualmente representa um grande desafio, pois gera demandas sociais, familiares e econômicas, além da necessidade de reestruturação de serviços de saúde com ações específicas a esta população (MIRANDA et al, 2016; DUTRA e SANCHEZ, 2015).

O Brasil vem se destacando no processo de transição demográfica e epidemiológica de forma muito acelerada, em comparação a outros países da Europa. O número de idosos no Brasil, ou seja, pessoas com 60 anos ou mais passou de 3 milhões em 1960, para 7 milhões em 1975, e 14 milhões em 2002 e deverá alcançar 32 milhões em 2020 (VERAS e OLIVEIRA, 2018). As projeções indicam que em 2020, o Brasil será a sexta maior população de idosos no mundo (KÜCHEMANN, 2012).

Com o processo de envelhecimento, pode haver um declínio no nível de higiene bucal e por consequência um aumento da incidência de doenças bucais em idosos. Algumas das condições associadas a este declínio são: diminuição da capacidade motora, a baixa autoestima, a falta de estímulo para a realização da higiene bucal, o comprometimento sensoriais e a perda da função cognitiva. Assim o cuidado à saúde bucal é uma construção cotidiana que precisa ser abordado de forma integral a medida que perdemos funções e habilidades ao longo da vida (GONÇALVES et al, 2010).

Nesse contexto, a saúde bucal apresenta grande relevância, pois interfere diretamente no bem estar físico, mental e social do indivíduo e, portanto necessita de atenção especial. A higienização bucal precária pode desencadear cárie e outras complicações, além de infecções localizadas, como periodontite e gengivite, que podem contribuir para a piora da qualidade de vida, principalmente em pessoas idosas (PUTURIDZE et al, 2018).

Ademais, a boca é passível de colonização pela microbiota adquirida em ambiente hospitalar, fato que pode se relacionar com a ocorrência de pneumonias aspirativas, particularmente em pessoas idosas que se encontram em condições de fragilidade e hospitalizadas (EWAN et al, 2015).

A manutenção da saúde bucal torna-se indispensável para boa qualidade de vida durante o envelhecimento e para tanto é necessário o estabelecimento de uma rotina de higiene bucal adequada e eficiente (KOKUBU et al, 2008).

O grande desafio da atualidade é a oferta de cuidados de higiene bucal à pessoa idosa dependente, em especial as que se encontram hospitalizadas ou institucionalizadas, visto que esse tipo de atenção em saúde está relacionado diretamente à presença de um cuidador que deveria estar capacitado para este tipo de cuidado específico (LAPARIDOU et al, 2018).

As dificuldades relacionam-se à falta de conhecimento específico de muitos cuidadores acerca do assunto, visto que habitualmente desconhecem a importância das medidas preventivas direcionadas à manutenção da saúde bucal, bem como os métodos de execução da higiene de dentes e próteses dentárias em pessoas idosas, particularmente as que se encontram dependentes para esta atividade de autocuidado (SANTOS et al, 2008). Tendo em vista as necessidades de cuidados com a saúde bucal em idosos, o presente estudo teve por objetivo identificar o conhecimento e práticas em saúde bucal realizada por cuidadores familiares de idosos. 


\section{METODOLOGIA}

Trata-se de estudo observacional descritivo, transversal, desenvolvido em uma unidade de internação de um hospital de ensino de Brasília, Distrito Federal, durante o período compreendido entre os meses de fevereiro a maio de 2016.

A população estudada foi constituída por cuidadores familiares que prestavam cuidados diretos às pessoas idosas internadas em um hospital universitário. A amostra foi obtida por conveniência e composta por 44 participantes. Foram excluídos do estudo acompanhantes de idosos ou cuidadores que não prestavam os cuidados diretos relacionados ao objeto da pesquisa.

Os dados foram coletados no formato de entrevista individual com os cuidadores dos idosos, por meio de instrumento do tipo formulário, construído para a pesquisa com as seguintes variáveis: sociodemográficas (gênero, idade, estado civil, escolaridade), relação com o idoso, formação para ser cuidador, conhecimento e prática de cuidados relacionados a saúde bucal e higiene oral.

O banco de dados foi construído no programa estatístico Statistical Package for the Social Sciences for Windows - SPSS versão 19, e todas as análises foram realizadas nesse programa. Inicialmente, foi realizada uma análise descritiva de todas as variáveis do estudo, por meio de distribuição da frequência absoluta e percentual.

O projeto de pesquisa foi submetido à apreciação do Comitê de Ética em Pesquisa da Faculdade de Ciências da Saúde da Universidade de Brasília e foi aprovado sob o protocolo CAAE:49929215.0.0000.0030. A abordagem e o convite aos cuidadores para participação na pesquisa foi realizado na unidade de internação do hospital, onde foram informados acerca dos objetivos e procedimentos de coleta de dados, destacando que seria uma participação voluntária. Após o consentimento, era apresentado o termo de consentimento livre e esclarecido (TCLE) para assinarem em duas vias, sendo uma via para o pesquisador e outra para 0 cuidador, participante da pesquisa.

\section{RESULTADOS}

Foram entrevistados 44 cuidadores familiares, sendo a grande maioria mulheres (89\%), com idade entre 20 e 39 anos (43\%), casados (70\%) e que apresentam como grau de escolaridade o ensino médio completo (55\%). Dos 44 entrevistados, 29 (66\%) são filhos dos idosos, 34 (77\%) residem com os mesmos e 35 (80\%) identificaram-se como o cuidador principal (Tabela 1).

Cerca de 30 cuidadores (68\%) afirmaram prestar cuidados aos idosos por tempo igual ou inferior a 1 ano, e quase a totalidade afirmou não possuir capacitação formal para o cuidado direcionado à pessoa idosa (Tabela 1).

Na Tabela 2 há a descrição das respostas dos entrevistados acerca da atenção dispensada à saúde e higiene bucal, direcionadas ao idoso sob seu cuidado. Dos 44 idosos hospitalizados, 79,5\% apresentaram necessidade de auxílio para execução da higiene bucal; e em $68 \%$ dos casos, a higiene bucal era realizada pelos cuidadores. Entretanto, apenas $6 \%$ dos cuidadores havia recebido ou participado de aula ou treinamento sobre saúde bucal.

A maioria dos cuidadores famliares (70\%) relatou observar boas condições da saúde bucal do idoso, sem a identificação da necessidade de consulta ao cirurgião-dentista. Curiosamente, um quarto dos entrevistados relatou observar dificuldades mastigatórias, e 15\% deles observaram queixas durante a escovação dentária, como por exemplo, sangramento gengival. Contudo, em mais de $50 \%$ dos casos os cuidadores não sabiam ou não lembravam a data da última avaliação odontológica do idoso. Dos idosos que utilizavam próteses dentárias, somente $33 \%$ as retiravam para dormir e, em $59 \%$ dos casos, o cuidador higienizava a prótese uma vez ao dia (Tabela 2). 
Tabela 1 - Caracterização dos cuidadores de acordo com dados sociodemográficos, de relação com o idoso e capacitação para o cuidado, Brasília, Distrito Federal, Brasil, 2016 ( $n=44)$

\begin{tabular}{|c|c|c|c|}
\hline Variáveis & & $\mathbf{n}$ & $\%$ \\
\hline \multirow[t]{2}{*}{ Gênero } & Masculino & 5 & 11,4 \\
\hline & Feminino & 39 & 88,6 \\
\hline \multirow[t]{4}{*}{ Idade (em anos) } & $20-39$ & 19 & 43,2 \\
\hline & $40-49$ & 12 & 27,3 \\
\hline & $50-59$ & 5 & 11,4 \\
\hline & $60-69$ & 8 & 18,2 \\
\hline \multirow[t]{3}{*}{ Estado civil } & Casado(a) & 31 & 70,4 \\
\hline & Solteiro(a) & 8 & 18,2 \\
\hline & Separado(a) & 5 & 11,4 \\
\hline \multirow[t]{4}{*}{ Escolaridade } & $\begin{array}{l}\text { Ensino fundamental } \\
\text { incompleto }\end{array}$ & 4 & 9 \\
\hline & Ensino fundamental completo & 4 & 9 \\
\hline & Ensino médio completo & 24 & 54,6 \\
\hline & Ensino superior & 12 & 27,3 \\
\hline \multirow[t]{5}{*}{ Grau de parentesco com o idoso } & Filho(a) & 29 & 66 \\
\hline & Esposo(a) & 4 & 9 \\
\hline & Irmão(ã) & 4 & 9 \\
\hline & Nora & 3 & 6,8 \\
\hline & Outros & 4 & 9 \\
\hline \multirow[t]{2}{*}{ É o (a) principal cuidador(a) } & Sim & 35 & 79,5 \\
\hline & Não & 9 & 20,5 \\
\hline \multirow[t]{2}{*}{ Reside com o idoso } & Sim & 34 & 77,3 \\
\hline & Não & 10 & 22,7 \\
\hline \multirow[t]{4}{*}{ Tempo como cuidador (a) do idoso } & 1 mês ou menos & 5 & 11,4 \\
\hline & $2-6$ meses & 13 & 29,5 \\
\hline & $7-12$ meses & 12 & 27,3 \\
\hline & Mais de 1 ano & 14 & 31,8 \\
\hline \multirow[t]{3}{*}{ Capacitação para cuidar de idosos } & Curso de cuidador de idosos & 1 & 2,3 \\
\hline & Outros treinamentos & 3 & 6,8 \\
\hline & Não & 40 & 90,9 \\
\hline \multirow{2}{*}{$\begin{array}{l}\text { O cuidador (a) já participou de curso/aula sobre } \\
\text { saúde bucal? }\end{array}$} & Sim & 3 & 6,8 \\
\hline & Não & 41 & 93,2 \\
\hline
\end{tabular}

Fonte: Dados da pesquisa, 2018. 
Tabela 2 - Caracterização do conhecimento, tipo de cuidado e práticas de higiene bucal executadas pelos cuidadores. Brasília, Distrito Federal, Brasil, 2016 ( $n=44)$.

\begin{tabular}{|c|c|c|c|}
\hline Questões & & $\mathbf{n}$ & $\%$ \\
\hline \multirow[t]{2}{*}{ O idoso(a) necessita ajuda para higiene bucal? } & $\operatorname{Sim}$ & 35 & 79,5 \\
\hline & Não & 9 & 20,5 \\
\hline \multirow[t]{2}{*}{ O idoso usa prótese dentária? } & Sim & 39 & 88,6 \\
\hline & Não & 5 & 11,4 \\
\hline \multirow[t]{2}{*}{ A prótese é retirada para dormir? } & Sim & 13 & 33,3 \\
\hline & Não & 26 & 66,7 \\
\hline \multirow[t]{3}{*}{ O idoso (a) apresenta queixas durante a higiene bucal? } & Sim & 7 & 15,9 \\
\hline & Não & 35 & 79,5 \\
\hline & Não sabe & 2 & 4,5 \\
\hline \multirow[t]{2}{*}{ O idoso apresenta dificuldade na mastigação, deglutição e fonética? } & Sim & 11 & 25 \\
\hline & Não & 33 & 75 \\
\hline \multirow[t]{2}{*}{ O cuidador observa no idoso algum problema bucal? } & Sim & 5 & 11,4 \\
\hline & Não & 39 & 88,6 \\
\hline \multirow[t]{2}{*}{ O cuidador percebe necessidade do idoso ir ao dentista? } & Sim & 13 & 29,5 \\
\hline & Não & 31 & 70,5 \\
\hline \multirow[t]{3}{*}{ O idoso tem acesso a serviços odontológicos? } & $\operatorname{Sim}$ & 26 & 59,1 \\
\hline & Não & 17 & 38,6 \\
\hline & Não sabe & 1 & 2,3 \\
\hline \multirow[t]{4}{*}{ Última consulta do idoso ao dentista } & até 1 ano & 13 & 29,5 \\
\hline & 1 a 2 anos & 4 & 9,1 \\
\hline & Mais de 2 anos & 3 & 6,8 \\
\hline & Não sabe & 24 & 54,6 \\
\hline
\end{tabular}

Fonte: Dados da pesquisa, 2018. 


\section{DISCUSSÃO}

O envelhecimento populacional vem trazendo maior oportunidade de convivência com doenças crônicas, que apresentam riscos de complicações e podem ser causa de incapacitação, dificultando ou impossibilitando o desempenho independente das atividades da vida cotidiana (DELWEL et al,2018).

A perda da independência implica na necessidade da presença de um terceiro para auxílio à realização das atividades básicas da vida diária (ABVD), como por exemplo, a higiene bucal. Um estudo realizado com pessoas idosas hospitalizadas devido fratura de membros inferiores demonstrou que a higiene bucal é pior naqueles que são dependentes, e a piora progride de forma diretamente proporcional ao tempo de hospitalização (MARTINEAU e PLARD, 2018).

A grande maioria dos serviços e cuidados prestados aos idosos advém de cuidadores oriundos de redes informais de apoio, como filhos, parentes e amigos, constituindo a fonte mais importante de suporte (EWAN et al, 2016; NARDI e OLIVEIRA, 2009). Evidenciou-se no presente estudo a presença do cuidador principal com perfil predominantemente pertencente ao gênero feminino, jovem, sendo em sua maioria as próprias filhas que residiam com o idoso, destacando o papel social da mulher junto à função do cuidado.

Os resultados encontrados demonstraram que cerca de $80 \%$ dos idosos necessitavam de auxílio para realização da higiene bucal, de acordo com as respostas de seus cuidadores. Em 68\% dos casos, era o cuidador quem realizava essa tarefa. Entretanto, a eficiência da higiene realizada no estudo em questão não foi mensurada. Além disso, a grande maioria dos idosos do estudo utilizava prótese dentária (88\%), enquanto pouco mais da metade dos cuidadores $(58 \%)$ a higienizam uma vez ao dia, somente.

A higiene da língua foi realizada por menos da metade dos cuidadores e as próteses foram retiradas durante o sono noturno somente por um terço dos idosos. Esses números demonstram que nem todos os idosos que necessitam de auxílio para a realização da higiene bucal o recebem; e é provável que os cuidadores deixem de dar atenção à detalhes importantes, como a higiene de próteses e da língua, pois na maioria dos casos já se encontram sobrecarregados com outras funções que muitas vezes julgam mais importantes, como por exemplo a administração de um medicamento.

As próteses dentárias devem ser retiradas para que sejam escovadas e também durante o sono, a fim de permitir oxigenação dos tecidos e minimizar o risco de infecções como a candidose bucal, pois atuam como reservatórios de microrganismos (OLIVEIRA et al, 2006). A limpeza da língua também é de extrema importância para diminuição da formação da saburra lingual, que é composta por restos alimentares, células epiteliais descamadas e microrganismos, diminuição do paladar e halitose, além de estar associada à maior risco de ocorrência de pneumonias aspirativas (PRZYLYNKI et al, 2009). Dessa forma, higiene bucal realizada de forma adequada em pessoas idosas, particularmente as hospitalizadas e institucionalizadas, pode limitar ou até mesmo impedir a ocorrência de agravos às condições da saúde geral (PRZYLYNKI et al, 2009; TAJIMA et al, 2017).

A realização da escovação dentária e o uso de fio dental requer conhecimento, habilidade motora, dedicação e técnica apropriada, capaz de desorganizar o biofilme bacteriano aderido às estruturas bucodentárias (AMARAL et al, 2009).

Contudo, quase a totalidade dos cuidadores entrevistados relatou nunca ter participado de curso de cuidadores ou ter recebido orientações sobre saúde bucal do idoso, a despeito da maioria ter cursado até o ensino médio. Apenas um cuidador relatou ter realizado curso formal, o que evidencia uma lacuna sobre o assunto e evidente falta de treinamento. $O$ grau de escolaridade interfere diretamente na prestação dos cuidados, uma vez que o cuidador necessita seguir dietas, prescrições e manusear medicamentos, funções exercidas com maior segurança quando há maior conhecimento (SILVA-JUNIOR et al, 2017).

A capacitação do cuidador familiar é uma necessidade urgente da sociedade atual, no entanto, há carência de programas ou cursos de capacitação abertos a comunidade e ainda as famílias se deparam com adversidades financeiras, emocionais e de práticas cotidianas de difícil manejo (LAPARIDOU et al, 2018). 
Cuidadores formais contratados também têm exercido função no cuidado à pessoa idosa, porém nem sempre são qualificados e treinados para dispensação do cuidado, em particular aquele relacionado à execução da higiene bucal. Esses obstáculos surgem devido à falta de conhecimento e de treinamento sobre as condições enfrentadas pelo envelhecimento ou mesmo pelas condições patológicas dos idosos assistidos por eles (LAPARIDOU et al, 2018). É provável que, por esse motivo, seja frequente a citação de dificuldades para a realização da higiene bucal de pessoas idosas dependentes.

O cuidado dispensado à higiene bucal em pessoas idosas dependentes, quando realizado por um profissional, quase sempre é executado por um técnico de nível fundamental ou médio, sendo pouco valorizado, considerando a quantidade de situações desestabilizadoras da saúde, que demandam cuidados intensivos. Assim, a saúde bucal situa-se em segundo plano frequentemente, sendo os procedimentos de higiene bucal executados conforme as concepções pessoais ou culturais, e muitas vezes, caracterizando um cuidado negligenciado (SANTOS et al, 2008).

Essa situação cria uma lacuna no processo de cuidado, permitindo que as más condições de saúde bucal sejam um fator adicional de aumento de custo, sofrimento e agravamento do quadro clínico (NAKATANI et al, 2003). Dessa forma, o idoso dependente tende a apresentar condições bucais insatisfatórias em relação ao independente, por não realizar seu autocuidado (SANTOS et al, 2008).

Dos cuidadores entrevistados, a grande maioria não observou qualquer problema bucal no idoso sob seus cuidados e $70,5 \%$ não identificaram a necessidade de consulta odontológica. Curiosamente, $30 \%$ dos cuidadores apontaram dificuldades mastigatórias e 15\% identificaram queixas como o sangramento durante a escovação dentária e xerostomia. Esses achados podem ser explicados pela aceitação da falta de saúde bucal como um processo inevitável e inerente ao envelhecimento (SEQUEIRA et al, 2013).

Além do desconhecimento acerca da importância da saúde bucal, e de técnicas de realização da higiene bucal, frequentemente há a sobrecarga do cuidador familiar, em função da sobreposição de papéis. Isso dificulta o cuidado dispensado ao idoso, pois o tempo dividido entre todas as atividades do cuidador pode gerar estresse físico e psicológico. Nessa situação, o cuidado muitas vezes é realizado como uma questão de obrigatoriedade (SILVA-JUNIOR et al, 2017).

É importante ressaltar que a saúde bucal é parte integrante da saúde geral, e uma vez comprometida, afeta o organismo como um todo, comprometendo a nutrição, a fala e o bem-estar físico e social do idoso.

\section{CONCLUSÃO}

Frente aos resultados apresentados, observou-se que idosos hospitalizados necessitam de auxílio, porém nem sempre os recebem adequadamente. Na população estudada, verificou-se maior número de cuidadores familiares, sem formação específica para atuação junto a cuidados em saúde bucal. Um dos desafios mais expressivos é oferecer cuidados adequados aos idosos e os que se tornaram dependentes e associado a essa demanda capacitar e orientar cuidadores de idosos quanto aos cuidados adequados sobre a saúde bucal parte essencial da saúde integral.

\section{REFERÊNCIAS}

1. MIRANDA GMD, MENDES ACG, SILVA ALA. Population aging in Brazil: current and future social challenges and consequences. Rev bras geriatr gerontol. 2016; 19( 3 ): 507-519.

2. DUTRA CESV, SANCHEZ HF. Organização da atenção à saúde bucal prestada ao idoso nas equipes de saúde bucal da Estratégia Saúde da Família. Rev bras geriatr gerontol. 2015; 18(1):179-188.

3. Veras RP, Oliveira M. Envelhecer no Brasil: a construção de um modelo de cuidado. Ciência \& saúde coletiva. 2018; 23(6): 1929-1936. 
4. Küchemann BA. Envelhecimento populacional, cuidado e cidadania: velhos dilemas e novos desafios. Sociedade e Estado. 2012; 27(1), 165-180.

5. Gonçalves LHT, Mello ALSF, Zimermann K. Validação de instrumento de avaliação das condições de saúde bucal de idosos institucionalizados. Esc Anna Nery. 2010; 14( 4 ): 839-847.

6. PUTURIDZE S, MARGVELASHVILI M, BILDER L et al. Relationship between general health, oral health and healthy lifestyle in elderly population (Review). Georgian med news.2018; Feb:17-21.

7. EWAN VC, SALLIS AD, WALLIS AW et al. Dental and microbiological risk factors for hospital-acquired pneumonia in non-ventilated older patients. PLoS One.2015; 29;10(4):e0123622.

8. KOKUBU K, SENPUKU H, TADA A et al. Impact of routine oral care on opportunistic pathogens in the institutionalized elderly. Journal of medical and dental sciences. 2008; 55(1).

9. LAPARIDOU D, MIDDLEMASS J, KARRAN T et al. Caregivers' interactions with health care services - Mediator of stress or added strain? Experiences and perceptions of informal caregivers of people with dementia - A qualitative study. Dementia (London). 2018; 1:1471301217751226.

10. SANTOS PSS, MELLO WR, WAKIM RCS et al. Use of Oral Rinse with Enzymatic System in Patients Totally Dependent in the Intensive Care Unit. Rev bras ter intensiva. 2008; 20 (2): 154-159.

11. DELWEL S, BINNEKADE TT, PEREZ RSGM et al. Oral Hygiene and Oral Health in Older People with Dementia: A Comprehensive Review with Focus on Oral Soft Tissues. Clinical oral investigations. 2018; 22 (1): 93-108.

12. MARTINEAU A, PLARD M. Successful aging: analysis of the components of a gerontological paradigma. Geriatr psychol neuropsychiatr vieil. 2018; Mar 1;16(1):67-77.

13. EWAN V, NEWTON JL, RUSHTON S et al. Oral hygiene of hospitalised older patients with limb lower fracture. Age and ageing.2016; 45: 887-890.

14. NARDI EFR, OLIVEIRA MLF. Significado de cuidar de idosos dependentes na perspectiva do cuidador familiar. Cienc cuid saúde. 2009; 8(3):428-435.

15. OLIVEIRA SK, LANDGRAF JUNIOR FJ, DELLAROZA MSG et al. Perfil dos cuidadores de idosos atendidos pelo Projeto de Assistência Interdisciplinar a Idoso em nível primário. Cienc cuid saúde. 2006; 5(2):184-192, 2006.

16. PRZYLYNKI DS, PELZER MT, SANTOS SSC et al. Ações educativas de enfermagem em saúde bucal de idosos em uma instituição de longa permanência. Cogitare enferm. 2009; 14(4):696- 702.

17. TAJIMA S, MASAHIRO R, KOICHIRO O et al. Time-dependent effects of tongue cleaning with mouthwash or mouth moisturising gel on the number of microbes on the tongue surface of elders with care needs. Gerodontology. 2017; 34 (4): 427-33.

18. AMARAL SM, CORTÊS AQ, PIRES FR. Nosocomial pneumonia: importance of the oral environment. J bras pneumol. 2009; 35(11):1116-1124.

19. SILVA-JUNIOR MF, SOUSA ACC, BATISTA MJ et al. Oral health condition and reasons for tooth extraction among an adult population (20-64 years old). Ciênc saúde coletiva. 2017; $22(8$ ): 2693-2702.

20. NAKATANI AY, SOUTO CCS, PAULETTE LM et al. Perfil dos cuidadores informais de idosos com déficit de autocuidado atendidos pelo Programa de Saúde da Família. Rev eletr enferm. 2003; 5(1).

21. SEQUEIRA E, CHAO RS, MORAES MJT et al. Modelo de teleducação sobre cuidados com a saúde oral do idoso usuário de prótese total dental. Rev ABENO. 2013; 13(2):2-12. 